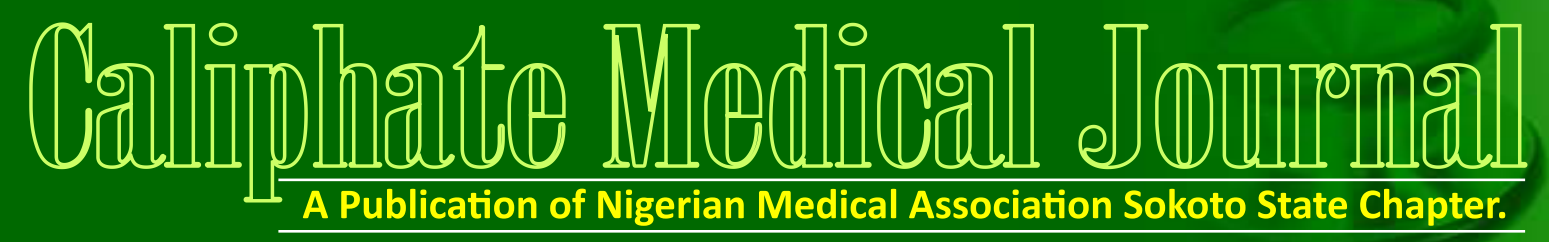

Vol 9, No. 4, October - December, 2021

ISSN: 2346-7193

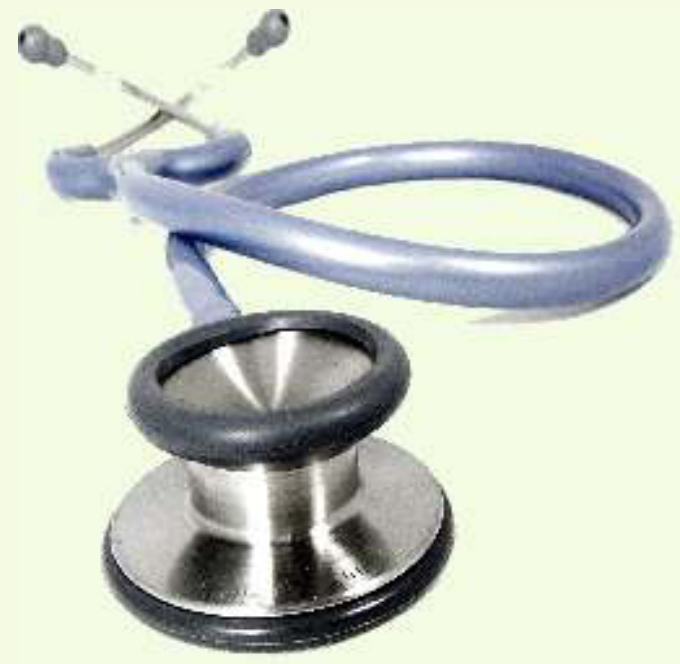

In this Issue
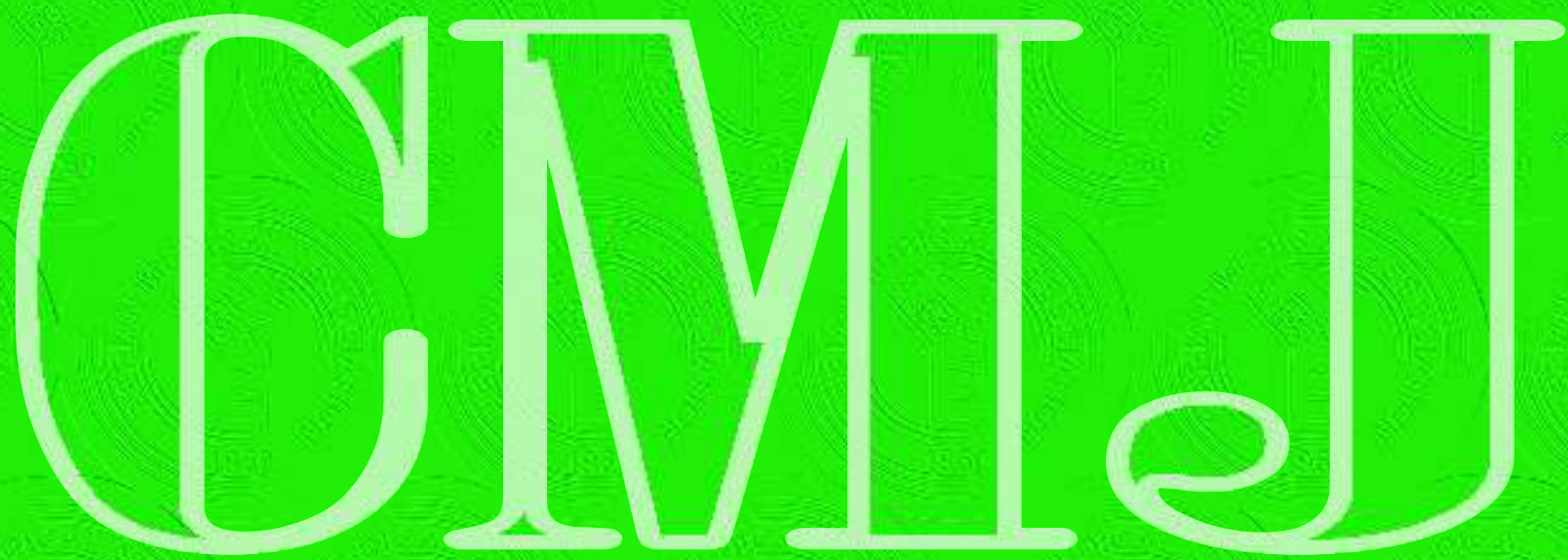


\title{
LIFE THREATENING KNIFE IMPALEMENT INJURY TO THE CRANIOFACIAL REGION: REPORT OF A RARE CASE
}

\author{
Bala M, Ogbeide ME, Taiwo AO, Ibikunle AA, Chukwuma BC, Sadeeq FA, Ndubuizu GU
} Jaafar R

Department of Dental and Maxillofacial Surgery,Usmanu Danfodiyo University Teaching Hospital PMB 2370, Sokoto, Nigeria

Corresponding Author's:

Bala Mujtaba,

Department of Dental and Maxillofacial Surgery, Usmanu Danfodiyo University Teaching Hospital PMB 2370, Sokoto, Nigeria E-mail: cdcsokoto456@gmail.com Phone: +234 8061267162

\section{ABSTRACT}

Assault due to various causes has been on the rise in our environment. We report a case of 28 -year-old Okada rider who was attacked by his passenger with knife. Examination revealed $35 \mathrm{~cm}$ long knife standing horizontally at the right supra zygomatic region with about $15 \mathrm{~cm}$ penetrating and passing below the zygomatic arch to reach the infratemporal fossa. There was complete loss of sensation of the right side of the tongue and the right side of the lower lip. The patient was taken to operation theater and right temporary external carotid ligation was done and the knife was removed with little bleeding from site of its penetration.

Keywords: Knife, Assault, Injury, Craniofacial

\section{Introduction}

$\mathrm{C}$ raniofacial injuries have heterogeneous etiology, impalement craniofacial injury in particular are uncommon, ${ }^{1-4}$ and causes may include gunshots, knives, missiles, shrapnel, and/or work-related accidents. ${ }^{2}$ Impalement injury have been described as a penetrating trauma by foreign object through hard or soft tissues with the object still remaining in a part of the wound and mostly conspicuous. ${ }^{4,5}$

Incidence of assault due to various causes has been on the rise in our environment. We report a case of 28-year-old Okada (commercial motorcycle) rider who was attacked by his passenger with knife on attempt to collect his motorbike

\section{Case Report}

A28-year-old okada rider presented to our hospital with a foreign body impalement injury to the right side of the craniofacial region secondary to an assault. He was said to have been attacked by his passenger on attempt to collect his bike. Patient was said to have bled profusely from the site of injury but the quantity of blood could not be ascertained. There was no history of seizures, convulsion or loss of consciousness. Patient reported complete loss of sensation of the lip and tongue on the right side.

Examination revealed the presence of a knife about $35 \mathrm{~cm}$ long and about $15 \mathrm{~cm}$ penetrated along the right supra zygomatic area just $3 \mathrm{~cm}$ lateral to the outer canthus of the right eye, however no loss of vision or injury to the eye. There is cake blood around the right auricular region. Both objective and subjective assessment revealed anaesthesia of the right lingual and inferior alveolar nerves. Mouth opening was about $30 \mathrm{~mm}$.

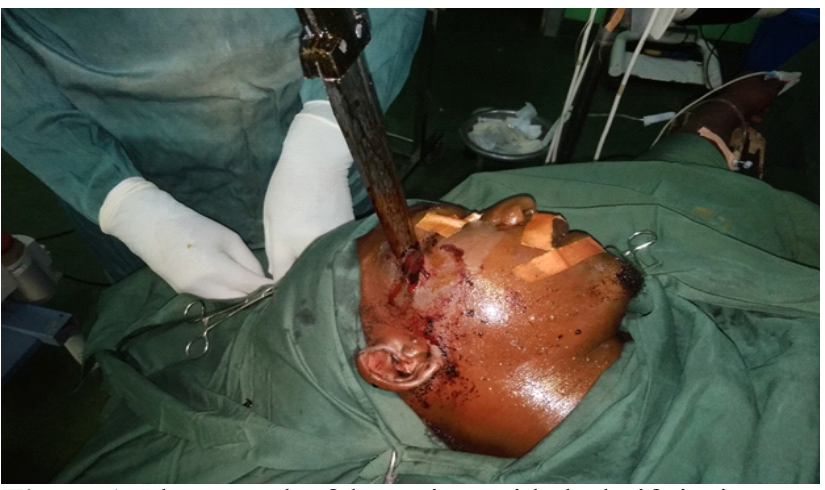

Figure 1: Photograph of the patient with the knife insitu
Vital signs at presentation include Blood pressure of 136/75 $\mathrm{mm} \mathrm{Hg}$, Pulse rate of 85 beat/minute, and respiratory rate of 20cycle per minute and temperature of 37 degree Celsius. Urgent Packed cell volume was requested which came out as 34 percent. Patient came with plain radiographs, however we requested for craniofacial computed tomography (CT scan) which was not done due to serious financial constraint. However, the available radiographs revealed the presence of radio-opaque object passing on the anterior surface of the zygomatic bone passing behind to reach the infratemporal fossa. Further routine hematological investigations revealed normal findings. Patient was taken to theater with 3.0 units of blood.

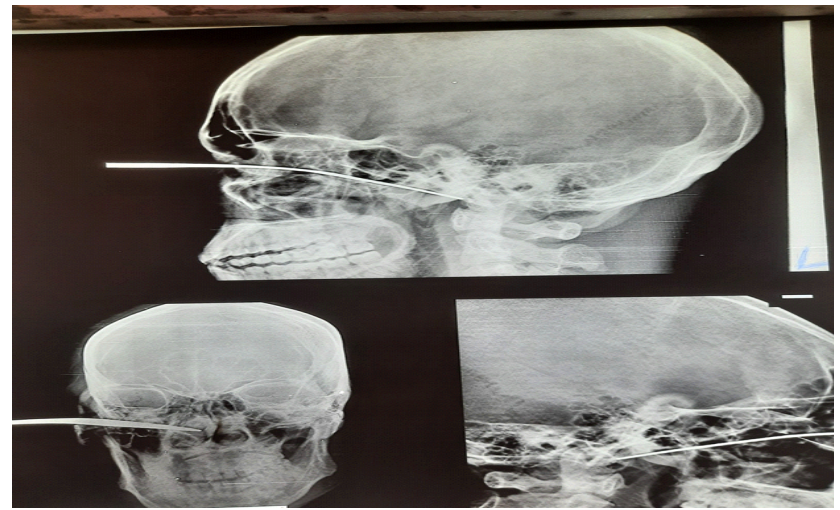

Figure 2: posterior anterior and lateral views of the skull showing the position of the knife impalement

Right temporary external carotid artery ligation was done, the knife was removed and the site was observed for 10 minutes for bleeding. Estimated blood loss for the procedure was $400 \mathrm{ml}$. Suturing done with vicryl 3.0 subcuticular and nylon 4.0 for skin. About 24hrs after surgery, patients complain of pain and abnormal sensation in the right ear. Ear, nose and throat surgeons were invited and their examination revealed otalgia and that was treated conservatively. Patient was discharge 4days after the surgery and since then has been on regular follow up.

\section{Discussion}

Intentional knife impalement injury to the craniofacial region also referred to as 'Jael syndrome ${ }^{3,4}$ is uncommon in the scientific literature ${ }^{3}$. The right-handed nature of most assailants has been attributed to the reason why these injuries are usually on the left side of the face ${ }^{4,6}$. However in this 
patient, the impalement was on the right. This may be due to the fact that the assailant attacked from behind thus striking the victim at an opposite side to most assailant who attack from the front.

Conventional plane radiographs and/ or CT is always required in these types of injuries, as they identify the course of the object and its correlation to vital anatomical structures. ${ }^{3}$ In this reported case, Plane radiographs shows a radiopaque object passing backward behind the maxilla into the infra-temporal fossa region.

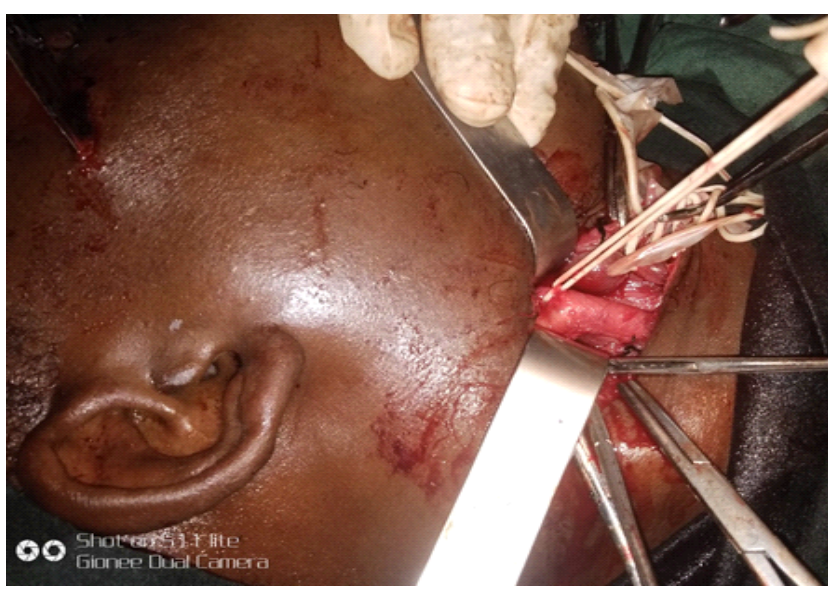

Figure 3: Temporal Externalcarotid artery ligation at the site of the knife inpalement

A key principle in managing an impaled object injury is the choice of using a controlled environment where an operation can be performed to control ensuing hemorrhage ${ }^{7}$. Attempt at retrieving an impalement object blindly should be discouraged as this could lead to fatal conscequences ${ }^{8}$. This among other reasons necessitated taking the patient to the operating theater and surgery done under general anesthesia. The choice of right temporary external carotid artery ligation was to minimize the risk of life-threatening, potentially uncontrollable hemorrhage. According to Salomone ${ }^{7}$ the knife could have acted as a tamponade to damage major blood vessels and its removal releases the pressure leading to life-threatening hemorrhage. Ibikunle et $\mathrm{al}^{9}$ reported use of external carotid artery ligation previously at the same health facility for both traumatic and neoplastic related surgeries with high propensity for significant intraoperative hemorrhage. This is further supported by Nasr ${ }^{10}$ who carried out bilateral external carotid artery ligation to control massive hemorrhage in a case of severe maxillofacial trauma.
Neurologic deficits observed in this patient include, complete loss of sensation of the right side of the tongue and the lower lip. Patient was discharge 4days after the surgery and has been on regular follow up for the past two (2) months.

\section{Conclusion}

Craniofacial impalement injuries are usually severe and may be life threatening due to proximity to several vital structures and the highly vascularized nature of this region, making it prone to severe hemorrhage. A prompt and adequate preoperative evaluation and intra-operative management is vital for optimal patient outcomes.

\section{Financial Support and Sponsorship}

Nil.

\section{Conflicts of Interest}

There are no conflicts of interest.

\section{References}

1. Voss JO, Thieme N, Doll C, Hartwig S, Adolphs N, Heiland M, Raguse JD. Penetrating Foreign Bodies in Head and Neck Trauma: A Surgical Challenge. Craniomaxillofac Trauma Reconstr. 2018 Sep;11(3):172-182. doi: 10.1055/s-0038-1642035. Epub 2018 Apr 24. PMID: 30087746; PMCID: PMC6078685

2. Quang CY, Rosal LM, Blair SG, Simmons JD, Rusyniak W G, Brevard SB. Craniofacial impalement injury: Projectile fragment to the head. Arch Trauma Res 2018;7:30-2

3. Dominguete PR, Matos BF, Meyer TN, Oliveira LR. Jael syndrome: removal of a knife blade impacted in the maxillofacial region under local anaesthesia. BMJ Case Rep. 2013; Apr 10; 2013. pii: bcr-2013008839. Doi: 10.1136/bcr-2013-008839.

4. Akhiwu BI, Adoga AS, Binitie OP, Ani CC, Iweagwu M, Adetutu O, Ureme T, George DD, Didamson PD, Oseni-Momodu E, Ugwu BT.Impalement Head Injury with a SpearJ West AfrColl Surg. 2016;6(2):113-124

5. Kulkarni A, Chandrasala S, Nimbeni B, Vishnudas P, Dev A. An Interesting Case of Penetrating Craniofacial Trauma Involving a Wooden Stick. J Clin Diagn Res. 2016;10(4):ZD01-ZD3.

6. Meer M, Siddiqi A, Morkel JA, Janse van Rensburg P, Zafar S. Knife inflicted penetrating injuries of the maxillofacial region: a descriptive, record-based study. Injury. 2010;41(1):77-81.

7. Salomone JP. More than skin deep: Use caution with impalement injuries. Journal of Emergency Medical Services. 2011;36:(6)

8. IbikunleAdebayo, Taiwo Abdurrazaq, Braimah Ramat,GbotolorunOlalekan.External carotid artery ligation: A useful arsenal in Maxillofacial surgery.Nigerian Journal of Oral and Maxillofacial Surgery 2017; 3:20-27.

9. Ugwu B. T. Arrow chest injuries in north central Nigeria - case series. West Afr J Med 2008; 27:160-163.

10. Nasr MM. Bilateral external carotid artery ligation: A life saving procedure in severe maxillofacial trauma. Int J Surg Case Rep. 2015;8C:81-83. doi:10.1016/j.ijscr.2015.01.021

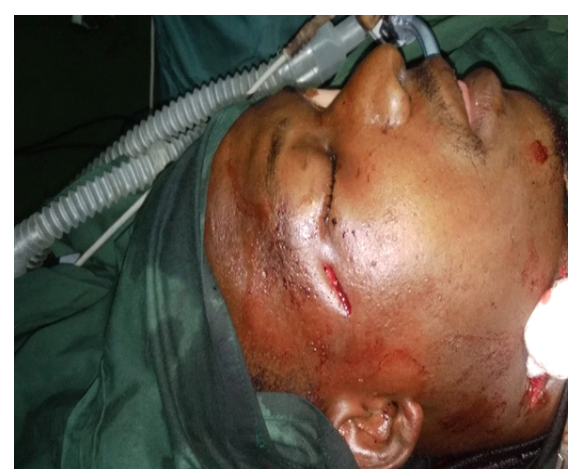

Figure 4: Patient photograph after the knife removal

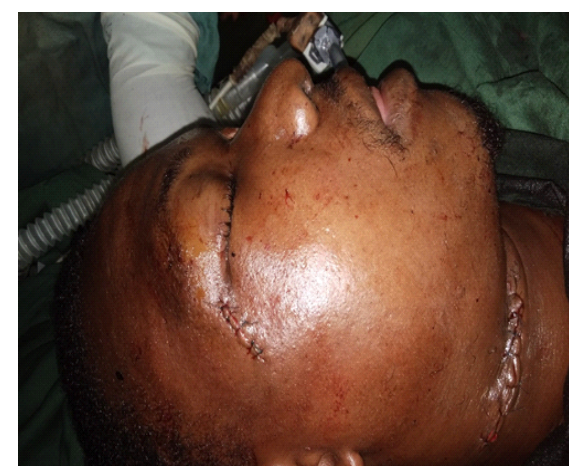

Figure 5: sutured impalement and ligation sites

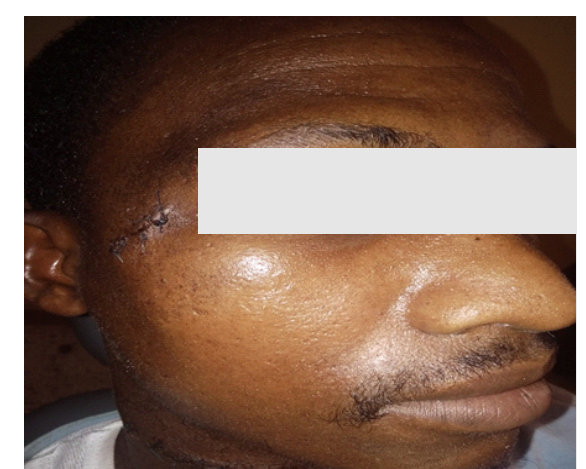

Figure 6: photograph of the patient 2 weeks post operation 